\title{
Agama Dan Ekonomi Kaum Tertindas
}

\author{
Muh. Yunus \\ Penulis adalah Dosen Fak. Tarbiyah Universitas Islam Negeri (UIN) Malang
}

\section{ABSTRACT}

As what Weber and Mc. Lelland view, it is assumed that values in certain religion and culture are believed to be able to influence the followers' behavior which are implied on the economic growth. Although indirectly they influence the economic development. Although Islam teaches about the work culture, the relity shows that Indonesian econmy has been well-develop yet.

Religion (Islam) as Weber critisizes, does not result in capitalism industrialization as the motivator of economic development because the culture is in line with "The Spirit of Capitalism ". It is different from Calvinism; its theology is able to move the economy development of its followers. Therefore, the Moslems' problem of economic decrease has to be solved with a right strategy. In this paper, the strategy used to solve the problem is macro analysis through the model of $M$. Chapra's "cycle theory".

\section{Agama dan Perilaku Ekonomi}

"Era persaingan ekonomi global bukan saja sudah tampak di depan kita, tetapi kini sudah terjadi". Tanda-tanda itu semakin jelas terutama ketika ekonomi India dan China mengalami kebangkitan. Selain Jepang, India dan China merupakan 
kekuatan baru yang sangat diperhitungkan dunia. Perekonomian kedua negara tersebut mengalami kemajuan yang sangat pesat, karena itu Ghoh Tjoh Tong mengibaratkannya seperti "Kuda Terbang" (Kompas, 20 April 2005).

India yang dulunya dikenal dengan sebutan Hindu rate of growh, pertumbuhan ekonominya hanya 3 persen setahun. Maka belasan tahun sesudah merdeka, India tetap menjadi negara miskin, bahkan lebih miskin dari Indonesia. Tetapi sejak sekitar 10 tahun terakhir ini, laju pertumbuhan Pendapatan Domestik Bruto (PDB) India rata-rata meningkat tajam hingga mencapai 6-7 persen setahun, dan kualitas Sumber Daya Manusia (SDM)-nya cukup tinggi (M. Sadli, Kompas, 25/5/2005: 4).

China adalah contoh lain yang mengagumkan. Kinerja perkonomiannya menjadi syndrome yang tak ada taranya di dunia. Selama tiga dasawarsa, PDBnya sempat tumbuh hingga 9 persen. Akibatnya, sebanyak 400 juta rakyat miskin berhasil terangkat dari kesengsaraannya. Karena itu, China oleh dunia dianggap sebagai ancaman, tetapi juga sekaligus sebagai peluang baru. China yang dulunya menganut politik isolasi pada zaman Mao Tse Dong dengan komunisme yang radikal, kini negara itu membuka "Tirai Bambu"-nya, siap bersaing di pasar bebas (M. Sadli, Kompas, 25/5/2005: 4). Demikian pula dengan negara-negara di Eropa, kini terus berusaha memacu perekonomian globalnya dengan cara menggabungkan diri dalam Europe Union (EU). Intinya, setiap bangsa berusaha dapat tetap eksis di tengah persaingan yang tajam.

Untuk menghadapi persaingan itu, maka "kerja keras" saja (hard work) tidaklah cukup, tetapi juga harus disertai dengan kerja cerdas (smart work). Dalam situasi seperti itu, hanya bangsa/individu yang memiliki keunggulan strategis yang mampu memenangkan persaingan pasar. Sementara bagi yang lemah, seolaholah mereka ditakdirkan harus terlempar dari pasar. Hukum ekonomi pasar memang memiliki watak seperti itu. Lantas bagaimana dengan posisi masyarakat Indonesia?

Sementara ini, masyarakat Indonesia yang nota bene adalah masyarakat beragama, mayoritas kondisi ekonominya justru masih tertindas. Untuk dapat bertahan saja mereka sudah susah, apalagi untuk memenangkan persaingan. Bila dibandingkan dengan Vietnam yang baru saja merdeka, daya saing SDM kita berada satu tingkat di bawahnya. Memang, di satu sisi pertumbuhan ekonomi kita mengalami kemajuan. Pemerintah merasa bangga bahwa pertumbuhan investasi 
pada kuartal pertama 2005 mencapai 14,5 persen. Realisasi investasi tersebut menjadi pemicu utama pertumbuhan ekonomi kita yang mencapai 6,35 persen. Akibatnya, Indonesia dinilai telah berhasil merebut kembali kepercayaan investor asing untuk menanamkan modalnya di Indonesia (Kompas, 25/5/2005: 13).

Tetapi di sisi lain, jumlah angka pengangguran masih cukup tinggi-sekitar 40 jutaan lebih-, bahkan belakangan ini kita dengar tidak sedikit warga di Nusa Tenggara Barat (NTB) yang meninggal karena penyakit "busung lapar". Sunguh ironis, NTB dikenal sebagai salah satu penghasil padi, tetapi rakyatnya banyak yang mati karena "busung lapar". Ibarat kata pepatah, "ayam mati kelaparan di atas lumbung padi". Masalahnya, mengapa India dengan masyarakat Hindunya dan China dengan masyarakat komunis-sosialisnya dapat maju; sementara Indonesia yang mayoritas masyarakatnya beragama (Islam) masih terpuruk? apakah ajaran agama di Indonesia dalam era persaingan ini sama sekali tidak memiliki relevansi terhadap kemajuan ekonomi para pemeluknya?

Studi tentang masalah itu pernah dilakukan oleh Max Weber yang dituangkan dalam bukunya yang sangat popular: The Protestant Ethic and The Spirit of Capitalism. Buku tersebut pertama kali diterbitkan dalam bahasa Jerman pada tahun 1905, kemudian diterjemahkan oleh Talcott Parsons pada tahun 1930. Pemikiran Weber itu masih menarik untuk dikaji lebih lanjut, terutama dalam Sosiologi Agama. Sementara di kalangan ekonom, Weber digolongkan ke dalam kelompok aliran historis yang dalam pembahasan ilmu ekonomi sudah banyak ditinggalkan (Deliarnov, 1993). Belakangan, pemikiran Weber kemudian dikembangkan oleh McLelland dalam karyanya yang juga popular: The Achieving Society (1961).

Baik Weber maupun Mclelland memiliki persamaan asumsi, bahwa nilainilai yang terkandung dalam agama atau budaya tertentu diyakini dapat mempengaruhi perilaku pemeluk atau masyarakatnya yang berimplikasi pada kemajuan ekonominya. Berdasarkan hasil-hasil studi empiris, menurut mereka memang mengindikasikan hal itu. Wujud dari perilakunya, misalnya tampak pada aktivitas ekonomi para wirausahawan yang memiliki "etos kerja" atau "motif berprestasi" tinggi. Studi-studi lain yang mengkaji hubungan agama dengan perilaku dan kemajuan ekonomi, misalnya Tokugawa Religion di Jepang.

Pendapat Weber tentang adanya pengaruh nyata doktrin Kristen Protestan terutama aliran Calvinis terhadap perilaku ekonomi memang mengundang 
perdebatan. Kritik-kritik tajam terhadap pendukung maupun penentang Weber di antaranya berasal dari Bryan S. Turner, Husein Alatas, R.H. Tawney, Kurt Samuelson, Andrew Greeley, dan lain-lain (lihat Taufiq Abdullah, 1993). Bahkan tidak sedikit pula yang mengganggap antara agama dengan ekonomi sama sekali tidak ada hubungan yang signifikan, karena logika/wilayah agama dengan logika/ wilayah ekonomi sangat berbeda.

Sebagian interpretasi Weber mengenai Islam yang dengan tajam dikritik oleh Turner adalah; "bahwa Islam tidak menghasilkan industrialisasi kapitalis sebagai mesin penggerak kemajuan ekonomi karena kebudayaannya tidak cocok dengan "semangat kapitalisme". Dengan kata lain, Weber menganggap bahwa teologi Islam tidak mengandung kekuatan sosial yang dapat menggerakkan ekonomi umatnya. Hal ini berbeda dengan golongan penganut Calvinisme yang diamati Weber, bahwa ajaran Calvinisme, menurutnya, adalah kunci utama dalam menentukan sikap hidup para penganutnya. Mereka memandang kerja sebagai beruf ("panggilan") atau "tugas suci", yakni "konsepsi agama" yang dimaknai sebagai tugas yang ditentukan oleh Tuhan, suatu tugas hidup, suatu lapangan di mana mereka harus bekerja". Hal ini sejalan dengan ajaran Calvinisme, bahwa "keselamatan" diberikan Tuhan kepada orang-orang yang terpilih. Oleh karena itu, para pemeluknya harus bekerja keras mengejar keselamatan itu, sebab keselamatan adalah salah satu pertanda mendapatkan rahmat dari Tuhan. Dalam kerangka pemikiran teologis seperti itu, maka "semangat kapitalisme" yang bersandar pada cita ketekunan, hemat, berperhitungan, rasional, dan sanggup menahan diri, menemukan pasangannya (Taufiq Abdullah, 1993).

\section{Islam dan Budaya Kerja}

Agama (Islam) dapat dipandang sebagai ajaran yang berisi nilai-nilai etik, moral dan spiritual yang dijadikan sebagai landasan hidup di segala bidang bagi para pemeluknya, tak terkecuali bidang ekonomi. Banyak sekali ajaran Islam yang mendorong agar umatnya mau bekerja keras untuk mengubah nasibnya sendiri. Misalnya perintah agar kita mau bekerja keras, dan Allah akan melihat hasil kerja kita itu (Q.S. At-Taubah: 105). Demikian pula Allah itu senantiasa sibuk (Q.S. Ar-Rahman: 29), maka seorang muslim harus sibuk bekerja. Kerja 
demikian harus disertai dengan keserasian lahiriah dan ruhaniyah, karena tanpa keserasian ruhaniyah (niat), maka kerja itu sia-sia belaka (Q.S. Al-Maidah:5).

Bahkan dinyatakan oleh Allah, bahwa untuk mendekati-Nya dapat dilakukan melalui kerja (Q.S. Al-Kahfi: 110). Karena itu Allah memerintahkan manusia agar jujur dalam berbisnis, adil, sukarela, tidak boleh ada penipuan (ghoror), dilarang mengurangi timbangan, dll. Islam juga menganjurkan agar umatnya mencari usaha dari tangannya sendiri, selalu berlomba-lomba dalam kebaikan, mengejar prestasi, dan kerja yang shaleh (amalan shaaliha). Ringkasnya, Islam memerintahkan berproduksi dan mengkonsumsi barang-barang yang halal dan bermutu. Hal itu sangat relevan dengan pesan Islam agar umatnya selalu terdorong untuk mengejar kebaikan dunia, tanpa melupakan akhiratnya.

Bila dicari, daftar nilai yang mengandung perintah bekerja keras dalam ajaran Islam masih dapat diperpanjang lagi. Idealnya, jika nilai-nilai di atas dapat diwujudkan dalam kehidupan sehari-hari, akan membentuk struktur sosial ekonomi yang makmur berkeadilan, atau dalam istilah agamanya "baldatun thayyibatun warabbun ghafur". Tetapi yang terjadi, selama ini masih terdapat masalah, yaitu kesenjangan antara ajaran Islam yang normatif (das solen) dengan realitas masyarakat muslim (das sein) yang kebanyakan masih tergolong kaum tertindas secara ekonomi.

Atas dasar itu, penulis berasumsi ada pengaruh, meski secara tidak langsung, antara agama dengan perilaku dan kemajuan ekonomi. Oleh karenanya, perlu dicari variabel lain yang secara bersama-sama dan sinergis dapat memacu kemajuan ekonomi suatu bangsa.

\section{Strategi Menggerakkan Ekonomi Umat: Analisis Makro}

Dalam bukunya yang terkenal, The Future of Economics: An Islamic Perspective (2001), M. Umer Chapra berhasil memperkenalkan sebuah model dinamika yang terinspirasi dari teori siklusnya Ibnu Khaldun mengenai sejarah perkembangan umat Islam. Menurut Chapra, kemajuan ekonomi umat dapat tercapainya apabila ada sinergi antara variabel-variabel sosial, ekonomi, politik, dan agama (syariah). Ia menyusun suatu rumusan bahwa bahwa peranan agama/ syariah (S), kekuasaan politik atau waazi' $(\mathrm{G})$, masyarakat atau rijal $(\mathrm{N})$, 
kekayaan/sumberdaya atau maal (W), pembangunan atau imarah $(\mathrm{g})$ dan keadilan atau 'adl (j) merupakan variabel-variabel penting yang mempengaruhi terwujudnya kemajuan atau kemunduran suatu bangsa, yang digambarkannya sbb:

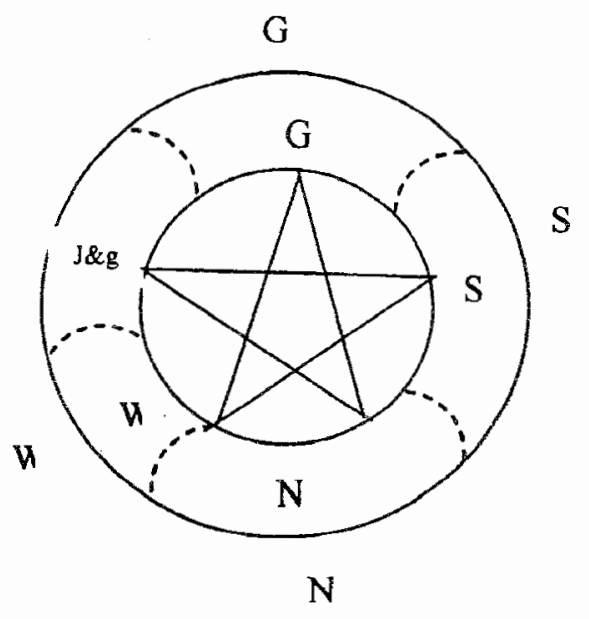

Sumber: Chapra. 2001. The Future of Economics: An Islamic Perspective. Jakarta: SEBI.

Dalam analisa jangka panjang, rumusan dalam gambar di atas tidak ada klausa cateris paribus karena tidak ada satu varaibel pun yang konstan. Variabel tersebut berada dalam suatu lingkaran yang saling tergantung karena satu sama lain saling mempengaruhi. Sebagai suatu siklus, lingkaran yang satu dapat dianggap sebagai siklus kemajuan, sedangkan yang lainnya sebagai siklus kemunduran, dan prosesnya dapat dimulai dari variabel manapun. Katakanlah sebagai siklus kemajuan, arahnya adalah S-N-W-j\&g-G-S. Tanamkan kesadaran agama/syariah $(\mathrm{S})$, kembangkan masyarakat sehingga terciptalah masyarakat $(\mathrm{N})$ yang paham syariah. Ini saja tentu tidak cukup. Langkah selanjutnya adalah meningkatkan kekayaan (W) masyarakat yang telah paham syariah itu. Bila hal itu tercapai, maka hal lainnya tidak dapat diabaikan, terutama pembangunan hukum dan keadilan (i\&g). Pada tahap ini, suatu bangsa telah memiliki modal berupa masyarakat yang paham syariah yang kaya dan berkeadilan. Tahap selanjutnya adalah menegakkan pemerintahan yang kuat (G) (Karim dalam Chapra, 2001: xvii). 
Bila dihubungkan dengan masyarakat Indonesia yang kondisi perekonomian umatnya masih terpuruk, ada sejumlah pelajaran yang bisa dipetik dari rumusan yang diperkenalkan Chapra tersebut:

Pertama, bahwa bangsa yang maju dan sejahtera, adalah bangsa yang di pimpin oleh penguasa politik $(G)$ yang bertanggung jawab dan berpihak pada rakyat. Mengapa para penguasa mengabaikan tanggung jawabnya? Salah satu jawabannya adalah bahwa demokrasi yang menjamin good governance dan akuntabilitas selama Orde Baru tidak terwujud. Padahal, akuntabilitas sebagai bagian dari demokrasi (syura) semestinya dapat dijadikan sebagai motivasi para penguasa $(G)$ untuk menegakkan keadilan (j) dan pembangunan (g), guna menunaikan tugasnya bagi kesejahteraan rakyat $(\mathrm{N})$.

Otoritas politik menjadi “tirani" karena mekanisme demokrasi ekonomi tidak berjalan baik. Politik pembangunan yang dijalankan pemerintah (G) pada waktu itu hanya bertumpu pada pertumbuhan ekonomi dan mengabaikan pemerataan, berakibat mengalirnya kekayaan (W) hanya pada segelintir orang, apalagi diperoleh melalui praktek-praktek korupsi, kolusi dan nepotisme (KKN) yang justru memperparah keadaan. Dalam kondisi seperti itu, agama (S) tidak akan mampu memainkan peranan yang berarti, kecuali jika agama tersebut dijalankan dengan baik dan benar serta tidak memihak dalam pelaksanaannya.

Kedua, bahwa kurangnya akuntabiltas politik perlahan-lahan dapat memunculkan penyakit yang dapat merusak keadilan (j) dan pembangunan (g). Salah satu dampak penyakit itu adalah hilangnya kebebasan berpendapat sehingga rakyat tidak berani mengkritik penguasa. Dengan demikian, hubungan dekat antara penguasa $(\mathrm{G})$ dengan rakyatnya $(\mathrm{N})$ menjadi terganggu, maka kualitas rakyat menurun, tidak ada motivasi dan inovasi, sementara aktivitas ekonomi riil (W) tidak dapat berkembang mengikuti perkembangan kebutuhan rakyat $(N)$.

Ketiga, bahwa otoritas politik (G) tidak dapat memaksakan kehendak pribadinya kepada rakyat $(\mathrm{N})$. Usaha-usaha seperti ini justru merusak solidaritas, kerusuhan sosial, dan tidak mendukung bagi terciptanya atmosfir pembangunan manusia Indonesia seutuhnya dan masyarakat Indonesia seluruhnya.

Keempat, bahwa ketika rakyat dipinggirkan, pemerintah mulai kehilangan kepercayaan dan dukungan grass root, karena itu tidak mungkin lagi dapat mempertahankan kekuasaannya. Secara perlahan-lahan, pada gilirannya penguasa yang zalim tersebut justru ditumbangkan oleh rakyatnya sendiri. 
Kelima, agama (Islam) bukanlah penyebab kemunduran. Keinginan penguasa ( $G$ ) dengan menyiasati agama (S) untuk kepentingan pribadinya, adalah sebagaian faktor yang justru menyebabkan usaha-usaha perbaikan untuk rakyat menjadi tidak efektif. Dengan kata lain, agama sudah kehilangan apa yang oleh Hendropuspito (1994) disebut sebagai fungsi profetis atau fungsi kritis. Akibatnya, yang tersisa dari agama hanyalah tinggal "simbol" belaka. Dalam kondisi seperti itu, masyarakat ibarat "rumput kering" yang mudah terbakar. Di mana-mana sering terdengar adanya kerusuhan yang berbau SARA (Suku, Antargolongan, Ras, dan Agama). Kekuatan transformatifnya menjadi mandek, karena itu agama seolah-olah tidak memiliki kekuatan sosial sebagai pengubah dan penggerak pembangunan.

Gambaran di atas adalah salah satu contoh, bahwa variabel pemerintah (G) dianggap sebagai titik tolak pembangunan, diposisikan sebagai variabel dependent dalam suatu lingkaran. Jika ditulis dalam notasi matematis, maka rumusannya adalah sebagai berikut (Chapra, 201: 154):

$$
G=f(S, N, W, g \text { dan } j)
$$

Hubungan antar variabel dalam model di atas dapat diputar balik. Setiap variabel independent dapat dianggap sebagai variabel terikat, saat variabel lain dianggap sebagai variabel bebas. Hal ini mengisyaratkan bahwa pemicu runtuhnya suatu bangsa tidak sepenuhnya sama antara bangsa yang satu dengan bangsa yang lain. Dalam model di atas, variabel yang dianggap sebagai pemicu keruntuhan suatu bangsa adalah kegagalan penguasa politik (G), atau bisa juga disebabkan oleh kegagalan lain.

Jika suatu bangsa sedang mengalami siklus kemunduran, apa yang seharusnya dilakukan? Dengan strategi yang tepat, maka siklus kemunduran tersebut dapat dibalik menjadi siklus kemajuan. Misalnya, menurunnya kesadaran masyarakat akan agama yang ditandai oleh rendahnya etos kerja, maraknya praktik KKN, dan lain-lain menjadi titik balik kesadaran masyarakat untuk kembali kepada agama (S). Maraknya kesadaran masayarakat untuk kembali kepada agama akan mendorong bangkitnya lagi masyarakat, sehingga siklusnya berubah menjadi siklus kemajuan, demikian seterusnya. 
Walhasil, bila perekonomian umat kita masih terpuruk, maka strategi penguatan ekonomi umat melalui peningkatan kesadaran agama perlu digalakkan. Ajaran agama yang relevan dengan budaya "etos kerja" dan "motif berprestasi" tinggi perlu terus ditekankan. Dari segi institusional, maraknya wacana dan praktek ekonomi Islam atau perbankan syariah adalah salah satu contoh agenda yang relevan untuk maksud itu, yakni untuk memperkuat ekonomi umat.

Tetapi yang perlu disadari, bahwa semua itu harus mampu berhadapan dengan invisible hand berupa "ekonomi pasar" yang sarat dengan persaingan. Artinya, kemajuan ekonomi umat tidak akan terwujud begitu saja hanya karena alasan iman (agama), tetapi harus melalui mekanisme pasar. Selain suprastruktur, pembangunan infastruktur yang mendukung terciptanya "mekanisme pasar" yang sehat sangat diperlukan. Karena itulah umat Islam harus mampu bersaing, ikut terlibat dan ikut mengarahkan "mekanisme pasar".

Salah satu contoh yang mungkin bisa dilakukan adalah menciptakan kreativitas atau inovasi-inovasi baru baik dari segi inovasi produk atau inovasi proses. Di sinilah relevansinya sistem ekonomi Syariah sebagai salah satu komplemen atau bahkan alternatif inovasi baru terhadap sistem ekonomi mainstream: kapitalis dan sosialis yang telah ada dan mengakar selama ini. Agama (Islam) tidak akan pernah maju, selama umatnya tidak mampu "mengoperasionalkan" ajaran agama yang normatif itu.

Dalam konteks itulah, sekali lagi, "persaingan ekonomi global itu bukan sudah dekat dengan kita, tetapi kini sudah terjadi". Maka mau tidak mau, kita harus berusaha keras mengejar ketertinggalan itu, mulai sekarang juga. Kita layak belajar dari India dan China, mengapa mereka yang dulunya relatif miskin, tetapi kini mampu "terbang" melampaui negara-negara tetangganya. Bila tidak, maka siklus kemunduranlah yang akan terjadi. Bagaimana dengan pandangan Anda? Wallahu A'lam. 


\section{Bibliography}

Chapra, M. Umer. 2001. The Future of Economics: An Islamic Perspective. Editor: M.I. Sigit Pramono, dkk.. Jakarta: Jakarta: SEBI.

Deliarnov. 1997. Perkembangan Pemikiran Ekonomi. Edisi Revisi. Jakarta: PT RajaGrafindo Persada.

Hendropuspito, D. 1994. Sosiologi Agama. Jakarta: Kanisius.

McLelland, David C. 1961. The Achieving Society. (Editor Stefan Suparna). 1987. Memacu Masyarakat Berprestasi: Mempercepat Laju Pertumbuhan Ekonomi Melalui Peningkatan Motif Berprestasi. Jakarta: Intermedia.

Sadli, M. "Ekonomi Asia dan Posisi Indonesia" . Artikel dalam harian KOMPAS, 25 Mei 2005.

Taufik Adullah (editor). 1993. Agama, Etos Kerja dan Perkembangan Ekonomi. Jakarta: LP3ES-Yayasan Obor.

"Indonesia Rebut Kepercayaan Dunia". Berita KOMPAS, 25 Mei 2005.

Weber, Max. 1930. The Protestan Ethic and Spirit of Capitalism. Diterjemahkan oleh Talcott Parsons. New York: Scribners. 